\title{
Kinetic and Thermodynamic Study of Arsenic (V) Adsorption on $P$ and $W$ Aluminum Functionalized Zeolites and Its Regeneration
}

\author{
Adriana Medina Ramírez ${ }^{1,2}$, Prócoro Gamero Melo ${ }^{1 *}$, José Manuel Almanza Robles ${ }^{1}$, \\ María Esther Sánchez Castro ${ }^{1}$, Sasirot Khamkure ${ }^{1}$, Roberto García de León ${ }^{3}$ \\ ${ }^{1}$ Sustainability of the Natural Resources and Energy, CINVESTAV Saltillo, Ramos Arizpe, Mexico \\ ${ }^{2}$ Nanotechnology Engineering, University of La Ciénega of the Michoacan State, Sahuayo, Mexico \\ ${ }^{3}$ Transformation Processes, Mexican Petroleum Institute, Mexico City, Mexico \\ Email: "pgamero@cinvestav.mx, anairdamr@gmail.com \\ Received May 29, 2013; revised June 3, 2013; accepted July 26, 2013
}

Copyright (C) 2013 Adriana Medina Ramírez et al. This is an open access article distributed under the Creative Commons Attribution License, which permits unrestricted use, distribution, and reproduction in any medium, provided the original work is properly cited.

\begin{abstract}
In the "Laguna" region of Coahuila state, Mexico like other places in the world, the groundwater needs to be treated to meet the quality required for human consumption. The study had probed that a Mexican fly ash can be used as a raw material to obtain effective low cost adsorbents for drinking water treatment, as well evaluated the effects of $\mathrm{pH}$, ion coexistence, dose, arsenic (As) concentration and temperature on the $\mathrm{As}(\mathrm{V})$ uptake by using $\mathrm{P}$ and $\mathrm{W}$ modified zeolites (PMOD and WMOD) obtained from a Mexican fly ash. The As(V) adsorption capacity of the WMOD zeolite was not affected by $\mathrm{pH}$ and $\mathrm{As}(\mathrm{V})$ concentrations in aqueous solution was achieved $<0.01 \mathrm{mg} / \mathrm{L}$ in the studied $\mathrm{pH}$ range; however, the $\mathrm{As}(\mathrm{V})$ removal by using PMOD zeolite decreased at high $\mathrm{pH}$ values. Carbonate concentration had a negative effect on the As(V) uptake of both zeolites but this effect was higher for the PMOD zeolite. The maximum adsorption capacities (Qmax) were 76.11 and $44.44 \mathrm{mg}$ of $\mathrm{As}(\mathrm{V}) / \mathrm{g}$ of zeolite for the WMOD and the PMOD zeolites, respectively. The adsorption process was endothermic, spontaneous and occurred by chemical exchange. The experimental data were best interpreted by a pseudo-second order kinetic model. The WMOD zeolite showed a higher adsorption capacity and rate than the PMOD even at the highest evaluated $\mathrm{As}(\mathrm{V})$ concentration. The adsorption capacity of the regenerated WMOD zeolite was similar to the original zeolite. Because of the high As(V) adsorption capacity, chemical stability and regenerability, the WMOD zeolite is potentially useful as low-cost adsorbent for $\mathrm{As}(\mathrm{V})$ removal from aqueous effluents.
\end{abstract}

Keywords: Fly Ash; Zeolite; Arsenic (V) Removal; Adsorbent Regeneration

\section{Introduction}

The amount of water that is usable for human activities is less than $3 \%$ of the total amount of water on earth. Rapid population growth and accelerated industrial development have led to a worldwide water crisis situation [1]. This problem is magnified in arid and semi-arid areas such as those prevailing in the northern Mexico, where the availability and quality of water resources are low. High-populated cities located in Coahuila are in the hydrologic-administrative region VII, which is provided from superficial water (32.6\%) and groundwater (67.4\%) [2]. The average supply per inhabitant is $125 \mathrm{~L} / \mathrm{day}$; this value is close to the minimum recommended by the

"Corresponding author.
World Health Organization (WHO) (100 L/day). Some important aquifers that provide water to the Coahuila are located in "Laguna" region, where the water is characterized by its high content of heavy metals such as arsenic (As) [3-5]. The water pollution is attributed to overexploitation and anthropogenic activities. It is well known that high concentrations of metallic salts in water affect human health and ecosystems. Several diseases have been related to $\operatorname{As}(\mathrm{V})$ exposure via drinking water, including skin lesions, neurological effects, hypertension, peripheral vascular disease and malignancies such as cancer of the skin, lung, bladder, kidney and uterus [6]. The reuse of wastewater is an alternative to mitigate the water scarcity, and the treatment of drinking water has become necessary to preserve human health in "Laguna" 
region in Coahuila, Mexico. Different techniques have been applied to remove $\mathrm{As}(\mathrm{V})$ from water, such as coagulation [7], ionic exchange resins [8-10], membrane process [11] and adsorption process [12-14], among others. In recent years, many investigations have been researching the development of low-cost and effective treatments using different materials such as biosorbents $[15,16]$, natural zeolites [14], activated alumina [17], portland cement [18], zero valent iron [19] and synthetic zeolites [20,21]. Synthetic zeolites could be provided a cost effective solution for toxic heavy metals removal [22].

Synthetic zeolites are typically obtained from relatively expensive chemical reagents or using byproducts with no commercial value but high amounts of alkali or long periods of time at high temperature. For instance, the $\mathrm{W}$ zeolite could be synthesized from alumina, colloidal silica, and potassium hydroxide by a hydrothermal method at $150^{\circ} \mathrm{C}$ for $48 \mathrm{~h}$ or using organometallic silicon and aluminum precursors with and without addition of organocations [23]. The $\mathrm{P}$ zeolite prepared from fly ash is typically obtained in mixture with residual crystalline phases such as mullite and quartz [24,25]. P Zeolite is obtained as a unique crystalline phase but a three-step synthesis procedure, long time and high temperature are required. The first step, the fly ash is fused with $\mathrm{NaOH}$ to convert the insoluble fly ash mineral phases to soluble chemical phases. The second step, an ageing process is carried out at $47^{\circ} \mathrm{C}$ for $48 \mathrm{~h}$. The third step is a hydrothermal treatment carried out at $140^{\circ} \mathrm{C}$ for $48 \mathrm{~h}$ [26].

Zeolites have been extensively applied in cationic species removal; however, few investigations have been made on the anionic species removal from aqueous effluents. Zeolites need to be functionalized to promote their capacity to uptake anionic species such as As(III) and (V). Functionalization with using expensive organic surfactants, aluminum or lanthanum modifiers of the zeolitic surface have been reported $[27,28]$.

The adsorption of metal ions on inorganic materials such as zeolites has been extensively investigated [29] but the aging and the regeneration of the exhausted material is rarely studied. Since the regeneration of the spent adsorbent enable to increases the adsorbent middle life and to contribute notably to reduce the cost of the water treating process, it is important to develop a regeneration process for each zeolite to re-establish the initial properties of the adsorbent for its effective reuse [30].

In a previous work, we reported the synthetic processes to obtain $\mathrm{P}$ and $\mathrm{W}$ zeolites from Mexican fly ash as unique crystalline phases [23]. The authors found that the $\mathrm{P}$ zeolite was obtained by a fusion method at one of the lowest ratio fly ash/ $\mathrm{NaOH}$, temperature and time. The $\mathrm{W}$ zeolite was synthesized by a new direct method with a low charge of $\mathrm{KOH}$, time and temperature, and without any organic template. The $\mathrm{W}$ zeolite was modified with a cheap aluminum salt (WMOD) and preliminary As (V) adsorption studies were done. In the present work, the functionalization with $\mathrm{Al}(\mathrm{III})$ of the $\mathrm{P}$ zeolite surface (PMOD), a detailed thermodynamic and kinetic studies of $\mathrm{As}(\mathrm{V})$ adsorption on both PMOD and WMOD functionalized zeolites, the aging of the WMOD zeolite surface by $\mathrm{As}(\mathrm{V})$ saturation, its regeneration by desorption of the $\mathrm{As}(\mathrm{V})$ and finally the reuse of the regenerated zeolite, are reported. The thermodynamic and kinetic parameters of PMOD and WMOD zeolites in the As(V) adsorption process are defined. It also concludes that WMOD zeolite is re-generable material and can be useful in the drinking water treatment from underground source in arid and semiarid region of Mexico and the world.

\section{Experimental}

\subsection{Materials and Chemical Reagents}

Mexican fly ash (MFA) was obtained from the "José López Portillo" coal-fired power plant located North in Coahuila state of Mexico. MFA was used as a raw material to synthesize the zeolite. A complete characterization of MFA was reported in a previous work [31]. Aluminum sulfate $\left[\mathrm{Al}_{2}\left(\mathrm{SO}_{4}\right)_{3}\right]$ was used for chemical functionalization of the zeolitic surface. As (V) solutions were prepared by dissolution of sodium arsenate

$\left(\mathrm{Na}_{2} \mathrm{HAsO}_{4} \cdot 7 \mathrm{H}_{2} \mathrm{O}\right)$ in deionized water. Sodium chloride $(\mathrm{NaCl})$, sodium carbonate $\left(\mathrm{Na}_{2} \mathrm{HCO}_{3}\right)$, calcium chloride $\left(\mathrm{CaCl}_{2}\right)$, sodium sulfate $\left(\mathrm{Na}_{2} \mathrm{SO}_{4}\right)$ and magnesium sulfate $\left(\mathrm{MgSO}_{4}\right)$ were used to evaluate the effect of ion coexistence on the $\mathrm{As}(\mathrm{V})$ adsorption. All reagents used were of reagent grade.

\subsection{Characterization of Zeolites}

The zeolitic products were characterized by X-ray diffraction (XRD) using a Philips model XPert PW3040 diffractometer. The morphology was examined by scanning electron microscopy using a Philips XL30 ESEM microscope. The chemical composition was measured by X-ray fluorescence (XRF) using a Bruker AXS spectrometer model S4 PIONNER. The concentration of residual As(V) was measured by plasma emission spectrophotometry (Thermo Elemental Instrumental, Iris Intrepid II) according to ASTM standard E-1097-07.

\subsection{Synthesis of Zeolites}

The $\mathrm{W}$ zeolite was obtained from MFA by straightforward zeolitization method. To obtain the P zeolite, MFA was thermally pretreated in presence of solid $\mathrm{NaOH}$ (fusion method) before carrying out the crystallization step. The bases for these synthesis methods were obtained 
from experimental design reported by our research group in Medina et al. [23]. The $\mathrm{W}$ zeolite was synthesized as follows: $160 \mathrm{~g}$ of MFA was added to $480 \mathrm{~mL}$ of $\mathrm{KOH}$ solution, maintaining a $\mathrm{KOH} / \mathrm{MFA}$ ratio of 0.33 . The mixture was transferred to a $\mathrm{Parr}^{\mathrm{TM}}$ reactor with a capacity of $1 \mathrm{~L}$. A hydrothermal treatment was then performed at $175^{\circ} \mathrm{C}$ for $16 \mathrm{~h}$. To obtain the $\mathrm{P}$ zeolite, MFA (76 g) was mixed with $\mathrm{NaOH}$, maintaining a $\mathrm{NaOH} / \mathrm{MFA}$ ratio of 1.04 . The mixture was homogenized and heated at $600^{\circ} \mathrm{C}$ for $2 \mathrm{~h}$. The resultant fusion product was then added to a flask containing $630 \mathrm{~mL}$ of deionized water and aged for $17 \mathrm{~h}$ at room temperature. The aged product was crystallized at $120^{\circ} \mathrm{C}$ for $16 \mathrm{~h}$. Both crystallization products were recovered and washed 3 times with $200 \mathrm{~mL}$ of deionized water. The final products were dried at $120^{\circ} \mathrm{C}$ for $12 \mathrm{~h} ; 160 \mathrm{~g}$ of the $\mathrm{W}$ zeolite and $77 \mathrm{~g}$ of the $\mathrm{P}$ zeolite were obtained.

\subsection{Functionalization of the Zeolitic Surface}

The chemical modification of the zeolitic surface was performed according to the method reported by $\mathrm{Xu}$ et al. [32]. Ten grams of zeolite was added to $1 \mathrm{~L}$ of an $\mathrm{Al}_{2}\left(\mathrm{SO}_{4}\right)_{3} 7 \mathrm{mM}$ solution and was stirred at room temperature $\left(23^{\circ} \mathrm{C}\right)$ for $15 \mathrm{~h}$. Subsequently, the modified zeolite was washed three times with $200 \mathrm{~mL}$ of deionized water, filtered and dried at $110{ }^{\circ} \mathrm{C}$ for $12 \mathrm{~h}$. Nine grams of each modified zeolite was obtained and labeled as WMOD and PMOD.

\subsection{Adsorption of $A s(V)$ on Modified Zeolites}

\subsubsection{Effect of $\mathbf{p H}$}

The initial $\mathrm{pH}$ of the $\mathrm{As}(\mathrm{V})$ solution was varied from 3 to 10 for both the WMOD and PMOD zeolites. One gram of zeolite was added to $100 \mathrm{~mL}$ of $0.72 \mathrm{mg} / \mathrm{L} \mathrm{As}(\mathrm{V})$ solution. The slurry was stirred at $25^{\circ} \mathrm{C}$ for 2 and $5 \mathrm{~h}$ for the WMOD and PMOD zeolites, respectively. Afterward, an aliquot of $10 \mathrm{~mL}$ was taken to determine the residual As $(V)$ concentration. The zeolites were characterized by $\mathrm{XRD}$ to determine the structural changes due to $\mathrm{pH}$ variation.

\subsubsection{Effect of Ions Coexistence}

The groundwater in arid regions of Mexico presents a high content of ions such as calcium, magnesium, carbonates, sulfates and chlorides. To establish the basis of a process of drinking water treatment, the effect of these ions on $\mathrm{As}(\mathrm{V})$ adsorption was evaluated in model solutions at different concentrations of: $\mathrm{Ca}^{2+}, \mathrm{Mg}^{2+}$ and $\mathrm{SO}_{4}{ }^{2-}$ $(100,500$ and $100 \mathrm{mg} / \mathrm{L})$ and $\mathrm{Cl}^{-}$and $\mathrm{HCO}_{3}{ }^{1-}(100,300$ and $500 \mathrm{mg} / \mathrm{L}$ ). Salt was added to $100 \mathrm{~mL}$ of a $1.4 \mathrm{mg} / \mathrm{L}$ $\mathrm{As}(\mathrm{V})$ solution under stirring, and then $0.5 \mathrm{~g}$ of the WMOD zeolite was added. The mixture was stirred for 2 h. Then, an aliquot was taken to measure the $\mathrm{As}(\mathrm{V})$ con- centration. The same procedure was applied for the PMOD zeolite, but the zeolite dosage was $1 \mathrm{~g}$, the As(V) concentration was $0.72 \mathrm{mg} / \mathrm{L}$ and the adsorption time was $5 \mathrm{~h}$.

\subsubsection{Effect of Temperature and Zeolite Dosage}

To determine the adsorption capacity of $\mathrm{As}(\mathrm{V})$ on the modified zeolites, three temperatures were studied: $15^{\circ} \mathrm{C}$, $25^{\circ} \mathrm{C}$ and $35^{\circ} \mathrm{C}$. The experiments were performed in a constant temperature bath. The zeolite dosage was varied $0.05-1.2 \mathrm{~g}$ and was added to $100 \mathrm{~mL}$ of an $\mathrm{As}(\mathrm{V})$ solution of $0.72 \mathrm{mg} / \mathrm{L}$. The samples were stirred for $18 \mathrm{~h}$. The filtrates were analyzed for residual $\mathrm{As}(\mathrm{V})$ concentration.

\subsubsection{Effect of Arsenic Concentration}

Five different $\mathrm{As}(\mathrm{V})$ concentrations were evaluated (8.45, $1.45,0.72,0.45$ and $0.1 \mathrm{mg} / \mathrm{L})$, the dosage used was of 1 $\mathrm{g}$, except for the two last concentrations, where the dosage was $0.05 \mathrm{~g}$ and $0.01 \mathrm{~g}$, respectively. The zeolite was added to $100 \mathrm{~mL}$ of an $\mathrm{As}(\mathrm{V})$ solution under stirring and was kept for $8 \mathrm{~h}$. Aliquots of $10 \mathrm{~mL}$ were taken at different intervals of time.

\subsection{Accelerated Aging and Regeneration of the WMOD Zeolite Exhausted with As(V)}

The WMOD zeolite was aged using three high As(V) concentrations: 8,35 and $359 \mathrm{mg} / \mathrm{L}$. The experiments were performed with $100 \mathrm{~mL}$ of $\mathrm{As}(\mathrm{V})$ solution and $1 \mathrm{~g}$ of zeolite during a time period of $15 \mathrm{~h}$. For a concentration of $359 \mathrm{mg}$ of $\mathrm{As}(\mathrm{V}) / \mathrm{L}$, the adsorption time was $48 \mathrm{~h}$. The procedure was as follows: the zeolite was added to $100 \mathrm{~mL}$ of $\mathrm{As}(\mathrm{V})$ solution, this was kept under stirring for a time period. Then an aliquot of $10 \mathrm{~mL}$ was taken in order to determine the residual arsenic concentration. Afterward the zeolite was recovered and dried in air. Then, the zeolite was treated with fresh arsenic solution; this procedure was repeated until the zeolite was exhausted.

In the first step of the regeneration process $\mathrm{As}(\mathrm{V})$ was desorbed from the WMOD zeolite using $\mathrm{NaOH} 0.01 \mathrm{M}$ during a time period of $2 \mathrm{~h}$. In the second step the original active surface of the WMOD zeolite was regenerated with aluminum salt following the method described in the Section 2.4.

The adsorption capacity of the regenerated adsorbent WMOD was evaluated under the same conditions to determine the effect of the treatments to which the zeolite was subjected.

\section{Results and Discussion}

\subsection{Characterization of the WMOD and PMOD Zeolites}

The physicochemical properties of the unmodified and 
modified zeolites are summarized in Table 1. The Si/Al molar ratio of both zeolites decreased after the modification treatment due to an increase in the aluminum content. The textural properties of the $\mathrm{W}$ zeolite were affected by the surface modification (the specific surface area calculated by the BET method $\left(\mathrm{S}_{\mathrm{BET}}\right)$ and the pore volume decreased to approximately $40 \%$ ), whereas the $\mathrm{P}$ zeolite's textural properties were not affected.

This result could be related to the difference in the zeolite's structure and the positions of the extra-framework ions (Figure 1).

The W zeolite's structure is similar to that of merlinoite, a natural zeolite. The framework is built of double 8 -member rings laterally linked by 4 -member rings. This framework results in the formation of two types of cages [33]. According to the last refinement [34], three extraframework cation sites can be identified in merlinoite. One site is at the center of the buckled 8-member rings of the pau cage and has a high occupancy (M1) that is generally filled by $\mathrm{K}^{+}$ions. The other sites are two mirror positions above and below the flat 8-member ring window; the former (M2) has a reasonably high occupancy that is still available for $\mathrm{K}^{+}$, and the latter (M3) is inside of the 8-8 SBU with a low occupancy. There is disagreement among other authors about site M2, who indicate other additional positions, one of which is at the center of the pau cage and is usually filled by smaller cations $\left(\mathrm{Na}^{+}, \mathrm{Ca}^{2+}\right)$. Consequently, a high number of potassium ions occupy the center of the D8R (double eight-member rings); when these ions are exchanged with aluminum ions, they partially obstruct the entry of

Table 1. Zeolites physicochemical properties.

\begin{tabular}{cccccc}
\hline Zeolite & Si/Al & $\begin{array}{c}\text { Bulk } \\
\text { density } \\
\left(\mathbf{g} \cdot \mathbf{c m}^{-3}\right)\end{array}$ & $\begin{array}{c}\mathbf{S}_{\text {BET }} \\
\left(\mathbf{~ m}^{\mathbf{2}} \cdot \mathbf{g}^{-1}\right)\end{array}$ & $\begin{array}{c}\mathbf{V}_{\text {pore }} \\
\left(\mathbf{c m}^{3} \cdot \mathbf{g}^{-1}\right)\end{array}$ & $\begin{array}{c}\mathbf{A l}^{3+} \\
\mathbf{e x c h a n g e d} \\
\left(\mathbf{m m o l} \cdot \mathbf{g}^{-1}\right)\end{array}$ \\
\hline W & 2.05 & - & 28.48 & 0.132 & - \\
WMOD & 1.78 & 0.62 & 17.26 & 0.084 & 0.59 \\
P & 1.46 & - & 51.58 & 0.124 & - \\
PMOD & 1.15 & 0.45 & 51.24 & 0.148 & 0.85 \\
\hline
\end{tabular}

$\overline{\mathrm{S}_{\mathrm{BET}}=\text { specific surface area determined by BET method, } \mathrm{V}_{\text {pore }}=\text { total pore }}$ volume.

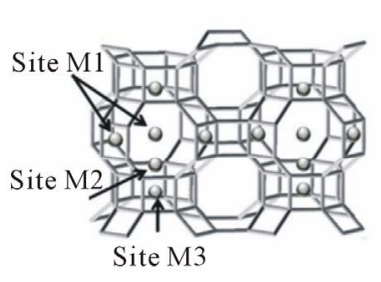

W zeolite

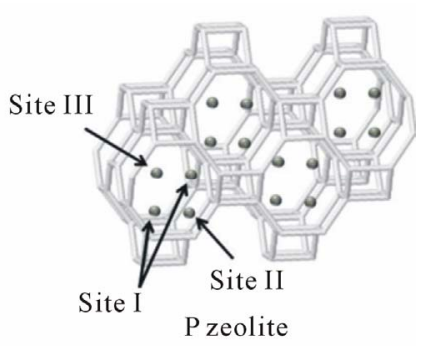

Figure 1. Extra-framework sites in the structure of the $W$ and $\mathbf{P}$ zeolites (Adapted from Mortier [37]). nitrogen to larger cavities, resulting in a decrease of the specific surface area.

However, the $\mathrm{P}$ zeolite has a similar structure to that of gismondine. This zeolite's framework is characterized by perpendicular double crankshaft chains of tetrahedra. These tetrahedra are connected at all corners, thus forming pore systems that consist of two eight-membered ring (8 MR) channels connected by four-membered rings (4 MRs). This topology has a high framework flexibility, which allows the accommodation of a wide range of extraframework cations $[35,36]$.

There are three sites for cations; sodium ions are located in both sides of the eight-ring channels, coordinated to the walls of both $8 \mathrm{MR}$ channels, allowing passage through the channels [36]. This behavior could explain the fact that the BET area was not modified after the exchange treatment.

\section{2. pH Effect on the As(V) Removal}

The effect of the initial $\mathrm{pH}$ on the $\mathrm{As}(\mathrm{V})$ removal is shown in Figure 2. The As(V) adsorption capacity of the WMOD zeolite was not affected by the initial $\mathrm{pH}$; the As (V) removal was higher than $98 \%$ for the range of $\mathrm{pH}$ evaluated $(3-10)$. The equilibrium $\mathrm{pH}$ was lower than 6 , with the exception of when the initial $\mathrm{pH}$ was 10 . The PMOD zeolite's As(V) uptake decreased at a $\mathrm{pH}_{\mathrm{o}}$ higher than 8. At $\mathrm{pH}_{\mathrm{o}}<8$, the $\mathrm{As}(\mathrm{V})$ removal was $90 \%$, whereas at $\mathrm{pH}_{\mathrm{o}}>8$, the $\mathrm{As}(\mathrm{V})$ removal was only $48 \%$.

According to Onyango et al. [27], when the effect of anionic adsorption is considered, the overall changes in the solution $\mathrm{pH}$ are related to the protonated $\left(\mathrm{AlOH}_{2}^{+}\right)$, neutral $(\mathrm{AlOH})$ and hydrolyzed $\left(\mathrm{AlO}^{-}\right)$surface sites present in the zeolite-metal surface. When the $\mathrm{pH}$ system

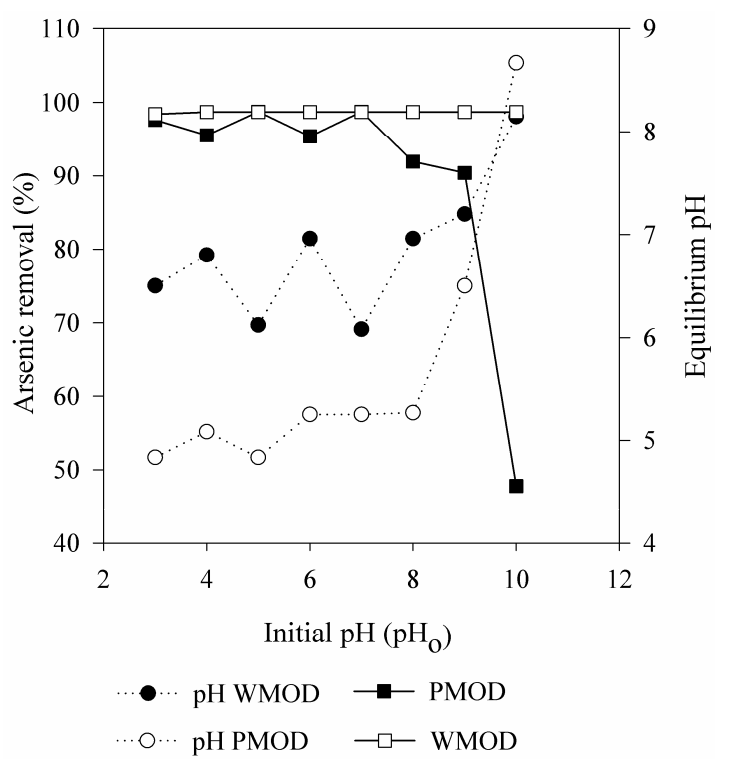

Figure 2. pH effect on $\mathrm{As}(\mathrm{V})$ adsorption on the functionalized zeolites $[\mathrm{Co}=0.72 \mathrm{mg} / \mathrm{L}$; dose $=1 \mathrm{~g} ; \mathrm{t}=5 \mathrm{~h}]$. 
decreases, the zeolite particles are positively charged, resulting in the consumption of hydroxyl ions, this enhances the $\mathrm{As}(\mathrm{V})$ uptake.

The observed differences for both zeolites can be related to the number of active sites that those materials possess. The WMOD zeolite has more active sites than the PMOD; therefore, the WMOD can adsorb not only As (V) species but also hydroxyl ions, which is inferred by the decrease of the $\mathrm{pH}$. It can be concluded that the zeolite type and the chemical nature of its surface are critical for a zeolite's chemical reactivity.

\subsection{Effect of the Coexistence of Ions}

The effect of $\mathrm{Ca}^{2+}, \mathrm{Mg}^{2+}, \mathrm{HCO}_{3}^{1-}, \mathrm{SO}_{4}^{2-}$ and $\mathrm{Cl}^{1-}$ ions on the $\mathrm{As}(\mathrm{V})$ uptake efficiency of the WMOD and PMOD zeolites is shown in the Table 2. The study was limited to the ranges of the ion concentrations reported in ground-water of "Laguna" region [3].

The presence of magnesium, sulfate and calcium had no significant effect on the As(V) removal of both zeolites.

The coexistence of chloride ions led to a decreasing efficiency of the PMOD zeolite, whereas for the WMOD, no significant changes were observed. Carbonate ions have an important effect on the $\mathrm{As}(\mathrm{V})$ uptake for both zeolites. However, this effect was more marked for the PMOD zeolite; an increase of 300 to $500 \mathrm{mg} / \mathrm{L}$ of carbonate ions led to decrease from $88 \%$ to $47 \%$ of this zeolite's $\mathrm{As}(\mathrm{V})$ adsorption capacity. For the WMOD zeolite, a reduction was observed only at concentrations higher than $1000 \mathrm{mg} / \mathrm{L}$, still using half $(0.5 \mathrm{~g})$ of the dose of zeolite compared to the PMOD zeolite (1 $\mathrm{g})$.

\subsection{Adsorption Isotherms}

Two models of isotherms, Langmuir and Dubinin Radushkevitch (DR), were used for the experimental data of the WMOD and PMOD zeolites. The Langmuir model is valid for a monolayer sorption on a surface with a finite number of identical sites: the Equation (1) is as follows:

$$
\left(\frac{1}{q}\right)=\left(\frac{1}{b q_{m} C_{e}}\right)+\left(\frac{1}{q_{m}}\right)
$$

where $C_{e}$ and $q$ are the equilibrium solute concentration $(\mathrm{mg} / \mathrm{L})$ and equilibrium adsorption capacity $(\mathrm{mg} / \mathrm{g})$ and $q_{m}$ and $b$ are the Langmuir constants representing the adsorption capacity $(\mathrm{mg} / \mathrm{g})$ and energy of adsorption $(\mathrm{L} / \mathrm{mg})$, respectively.

The parameters obtained from plots of $1 / C_{e}$ vs $1 / q$ are summarized in Table 3. The adsorption capacity and $b$ constant were increased when the temperature increased. The increase of the $b$ values indicates an endothermic nature of the adsorption process for both zeolites.

To distinguish the mechanism that takes place in the As $(\mathrm{V})$ uptake by the WMOD and PMOD zeolites, the Dubinin Radushkevitch (DR) isotherm model [38] was used with the experimental data. The isotherm DR has the following Equation (2):

$$
\ln Q=\ln Q_{m}-k \varepsilon^{2}
$$

where $\varepsilon$ is the Polanyi potential and is obtained by following Equation (3):

$$
\varepsilon=R T \ln \left(\frac{C_{0}}{C_{e}}\right)
$$

$Q$ is the amount of $\mathrm{As}(\mathrm{V})$ adsorbed per unit weight of adsorbent $(\mathrm{mg} / \mathrm{g}), Q_{m}$ is the adsorption capacity $(\mathrm{mg} / \mathrm{g})$, $\mathrm{C}_{e}$ is the equilibrium concentration of $\mathrm{As}(\mathrm{V})$ in an aqueous solutions, $C_{o}$ is the initial concentration, $K$ is a constant related to the adsorption energy, $R$ is the gas constant, and $T$ is the temperature (K). Figure 3 shows the plot of $\ln Q$ vs $\varepsilon^{2}$ for both zeolites. The $K$ and $Q_{m}$ values were obtained from the slopes and intercepts of linear curves at different temperatures. The maximum capacity adsorption $\left(Q_{m}\right)$ increased when temperature increased; the highest value was $76.11 \mathrm{mg} \mathrm{As}(\mathrm{V}) / \mathrm{g}$ and $44.44 \mathrm{mg}$ $\mathrm{As}(\mathrm{V}) / \mathrm{g}$ for the WMOD and PMOD zeolites, respectively. The value of $Q_{m}$ obtained for the WMOD zeolite was higher than that for $\mathrm{Zr}$ resin $(53.94 \mathrm{mg} / \mathrm{g})$ reported

\begin{tabular}{|c|c|c|c|c|c|c|c|c|c|c|}
\hline \multirow[b]{2}{*}{$\mathrm{Mg} / \mathrm{L}$} & \multicolumn{2}{|c|}{$\mathrm{Ca}^{2+}$} & \multicolumn{2}{|c|}{$\mathrm{Mg}^{2+}$} & \multicolumn{2}{|c|}{$\mathrm{SO}_{4}^{2-}$} & \multicolumn{2}{|c|}{$\mathrm{Cl}^{-}$} & \multicolumn{2}{|c|}{$\mathrm{HCO}_{3}^{-}$} \\
\hline & WMOD & PMOD & WMOD & PMOD & WMOD & PMOD & WMOD & PMOD & WMOD & PMOD \\
\hline 0 & 99.36 & 98.78 & 99.36 & 98.78 & 99.36 & 98.78 & 99.36 & 98.78 & 99.36 & 98.78 \\
\hline 100 & 99.36 & 98.11 & 99.36 & 96.76 & 99.36 & 96.89 & 99.36 & 92.03 & 99.36 & 88.38 \\
\hline 300 & - & - & - & - & - & - & 99.36 & 83.92 & 98.86 & 88.92 \\
\hline 500 & 99.36 & 97.97 & 98.14 & 96.08 & 98.29 & 97.30 & 99.36 & 88.51 & 97.21 & 47.97 \\
\hline 1000 & 99.36 & 97.97 & 97.79 & 96.76 & 97.43 & 98.11 & - & - & 91.28 & - \\
\hline 1500 & - & - & - & - & - & - & - & - & 82.50 & - \\
\hline 2000 & - & - & - & - & - & - & - & - & 63.57 & - \\
\hline
\end{tabular}
by Suzuki et al. [39] and modified calcined bauxite (1.12

Table 2. Effect of coexistence of ions on the percentage removal of As(V) on WMOD and PMOD zeolites.

Adsorption conditions: zeolite WMOD $[\operatorname{As}(\mathrm{V})]=1.4 \mathrm{mg} \cdot \mathrm{L}^{-1} ; \operatorname{dose}=0.5 \mathrm{~g} ; \mathrm{t}=2 \mathrm{~h}$; zeolite PMOD: $[\operatorname{As}(\mathrm{V})]=0.72 \mathrm{mg} \cdot \mathrm{L}^{-1} ; \operatorname{dose}=1 \mathrm{~g} ; \mathrm{t}=5 \mathrm{~h}$. 
Table 3. Langmuir parameters for $\mathrm{As}(\mathrm{V})$ adsorption on WMOD and PMOD zeolites.

\begin{tabular}{cccccccc}
\hline & \multicolumn{3}{c}{ WMOD Zeolite } & \multicolumn{3}{c}{ PMOD Zeolite } \\
\hline $\mathrm{T}\left({ }^{\circ} \mathrm{C}\right)$ & $q_{m}\left(\mathrm{mg} \cdot \mathrm{g}^{-1}\right)$ & $b$ & $R^{2}$ & $q_{m}\left(\mathrm{mg} \cdot \mathrm{g}^{-1}\right)$ & $b$ & $R^{2}$ \\
\hline 15 & 0.5906 & 62.7037 & 0.9383 & 0.5763 & 5.4603 & 0.9604 \\
25 & 0.4385 & 162.8571 & 0.9196 & 0.6337 & 12.7258 & 0.9801 \\
35 & 0.6747 & 247.00 & 0.9621 & 0.6729 & 13.7592 & 0.9601 \\
\hline
\end{tabular}
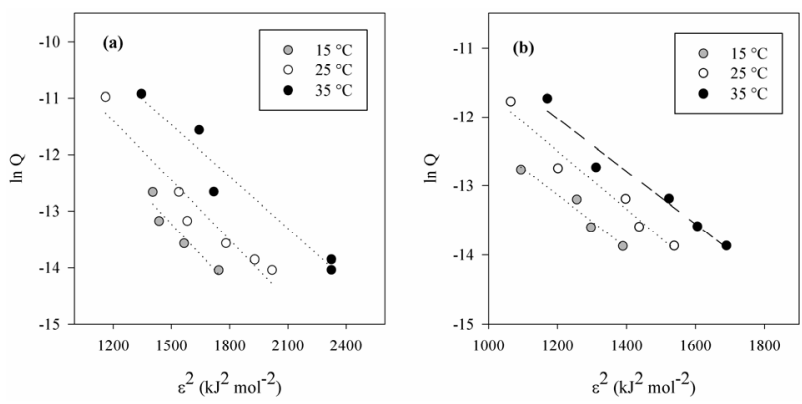

Figure 3. DR isotherms for $\operatorname{As}(\mathrm{V})$ adsorption on the (a) WMOD and (b) PMOD zeolites $\left[C_{o}=0.72 \mathrm{mg} \cdot \mathrm{L}^{-1} ; \mathrm{pH}_{0}=7\right.$; dose $=0.05-1.2 \mathrm{~g} ; \mathrm{t}=18 \mathrm{~h}$ ].

$\mathrm{mg} / \mathrm{g})[40]$.

To evaluate the nature of the interaction between $\mathrm{As}(\mathrm{V})$ and the binding sites, the mean energy of adsorption per mole of the sorbate $(E)$ was calculated by following Equation (4):

$$
E=(-2 k)^{-1 / 2}
$$

where $E$ is the free energy change when one mole of ion is transferred from an infinite solution to the surface of a solid. If this magnitude is between 8 and $16 \mathrm{~kJ} / \mathrm{mol}$, the adsorption process proceeds by ion exchange, whereas for values of $E<8 \mathrm{~kJ} / \mathrm{mol}$, the adsorption process is of a physical nature [39]. For both zeolites, at the three temperatures studied, $E$ was higher than $8 \mathrm{~kJ} / \mathrm{mol}$ (Table 4). Therefore, the As(V) uptake on the WMOD and PMOD zeolites occurs by an ionic exchange. The efficiency of the adsorption process was determined by a dimensionless equilibrium parameter $r$ by the next Equation (5):

$$
r=\frac{1}{1+b C_{0}}
$$

where $b$ is the Langmuir constant and $C_{0}$ is the initial concentration of $\mathrm{As}(\mathrm{V})$ in $\mathrm{mg} / \mathrm{L}$. A value $<1$ indicates a favorable adsorption, whereas a value $>1$ indicates an unfavorable adsorption. For both zeolites, the $r$ values were lower than 1, which means the adsorption of $\mathrm{As}(\mathrm{V})$ is favorable.

In addition to the isothermal adsorption, thermodynamic parameters such as the standard Gibb's free energy $\left(\Delta G^{\circ}\right)$, the enthalpy change $\left(\Delta H^{\circ}\right)$ and the entropy change $\left(\Delta S^{\circ}\right)$ were calculated to evaluate the feasibility and nature of the adsorption process.

According to the Langmuir model, adsorption occurs on active sites with the same energy level. The adsorption enthalpy and the corresponding Langmuir constant $b$ depend on the specific pair of adsorbent ions on the active site and on the temperature [41]. $\mathrm{As}(\mathrm{V})$ adsorption is a spontaneous process, the value of the Langmuir constant for adsorption reactions can be expressed according with the Equation (6):

$$
b=K_{0}=\left[\frac{-\Delta G^{\circ}}{R T}\right]
$$

The Gibb's free energy change is related to the enthalpy change and the entropy change at a constant temperature by the following Equation (7):

$$
\ln K_{0}=\frac{\Delta S^{\circ}}{R}-\frac{\Delta H^{\circ}}{R T}
$$

The thermodynamic parameters are shown in Table 5. For both the WMOD and PMOD zeolites, the enthalpy change was positive, which indicates that the process is endothermic. Negative values of $\Delta G^{\circ}$ confirm the feasibility of the process and its spontaneous nature. When $\mathrm{As}(\mathrm{V})$ ions react with an $\mathrm{AlOH}_{2}^{+}$ligand on the sorbent surface, water molecules previously bonded to the metal ion are released and dispersed in the solution, resulting in an increase in the entropy [42]. The positive change in the enthalpy and the entropy has been reported for the sorption of several heavy metals onto various low-cost adsorbents such as kaolinite [43] and activated carbon [44].

\subsection{Kinetic Studies}

The initial concentration of $\mathrm{As}(\mathrm{V})$ was varied to determine the kinetic parameters such as the adsorption rate constant $\left(k_{2}\right)$ and the mass transfer coefficient $(\beta)$ for $\mathrm{As}(\mathrm{V})$ adsorption on the WMOD and PMOD zeolites. The Ho's pseudo-second order kinetic model was used for the experimental data of both zeolites. According the following linearized Equation (8) [45].

$$
\frac{t}{q_{t}}=\frac{t}{k_{2} q_{2}}+\frac{t}{q_{2}}
$$

where $k_{2}$ is the rate constant of the pseudo-second order adsorption $\left(\mathrm{g} \cdot \mathrm{mg}^{-1} \cdot \mathrm{min}^{-1}\right)$. The values of the parameters of the pseudo-second order model were calculated from plots of $t / q_{t}$ against $t$ at different $\mathrm{As}(\mathrm{V})$ concentrations. These parameters are shown in the Table 6.

In all cases, the WMOD zeolite showed a higher adsorption capacity and rate than the PMOD zeolite, even at the highest concentration evaluated. The WMOD zeolite was able to diminish the $\mathrm{As}(\mathrm{V})$ concentration to levels lower than $0.01 \mathrm{mg} / \mathrm{L}$. The mass transfer coefficient was calculated according to Equation (9) [46]: 
Table 4. DR isotherm parameters for $\operatorname{As}(V)$ adsorption on WMOD and PMOD zeolites.

\begin{tabular}{|c|c|c|c|c|c|c|c|c|c|c|c|c|}
\hline \multirow{2}{*}{$\mathbf{T}\left({ }^{\circ} \mathbf{C}\right)$} & \multicolumn{2}{|c|}{$K \times 10^{3}\left(\mathrm{~kJ}^{2} \cdot \mathrm{mol}^{-2}\right)$} & \multicolumn{2}{|c|}{$Q_{\max }\left(\mathrm{mg} \cdot \mathrm{g}^{-1}\right)$} & \multicolumn{2}{|c|}{$r$} & \multicolumn{2}{|c|}{$E\left(\mathrm{~kJ} \cdot \mathrm{mol}^{-1}\right)$} & \multicolumn{2}{|c|}{ Process type } & \multicolumn{2}{|c|}{$R^{2}$} \\
\hline & WMOD & PMOD & WMOD & PMOD & WMOD & PMOD & WMOD & PMOD & WMOD & PMOD & WMOD & PMOD \\
\hline 15 & -3.616 & -3.84 & 30.48 & 14.90 & 0.021 & 0.120 & 11.76 & 11.41 & \multicolumn{2}{|c|}{ Ionic exchange } & 0.9094 & 0.9557 \\
\hline 25 & -3.518 & -4.21 & 57.12 & 43.87 & 0.080 & 0.098 & 11.92 & 10.90 & \multicolumn{2}{|c|}{ Ionic exchange } & 0.9439 & 0.9586 \\
\hline 35 & -3.056 & -3.82 & 76.11 & 44.44 & 0.005 & 0.091 & 12.79 & 11.43 & \multicolumn{2}{|c|}{ Ionic exchange } & 0.9446 & 0.9585 \\
\hline
\end{tabular}

Table 5. Thermodynamic parameters of As(V) adsorption on WMOD and PMOD zeolites.

\begin{tabular}{|c|c|c|c|c|c|c|c|c|}
\hline \multirow[t]{2}{*}{$\mathbf{T}\left({ }^{\circ} \mathrm{C}\right)$} & \multicolumn{2}{|c|}{$K_{L} \times 10^{-5}\left(\mathrm{~L} \cdot \mathrm{mol}^{-1}\right)$} & \multicolumn{2}{|c|}{$\Delta G^{\circ}\left(\mathrm{kJ} \cdot \mathrm{mol}^{-1}\right)$} & \multicolumn{2}{|c|}{$\Delta H^{\circ}\left(\mathrm{kJ} \cdot \mathrm{mol}^{-1}\right)$} & \multicolumn{2}{|c|}{$\Delta S^{\circ}\left(\mathrm{kJ} \cdot \mathrm{mol}^{-1} \cdot \mathrm{K}^{-1}\right)$} \\
\hline & WMOD & PMOD & WMOD & PMOD & WMOD & PMOD & WMOD & PMOD \\
\hline 15 & 4.698 & 0.760 & -36.785 & -32.424 & +50.757 & +11.282 & +0.305 & +0.152 \\
\hline 25 & 12.201 & 0.953 & -40.427 & -34.111 & & & & \\
\hline 35 & 18.506 & 1.039 & -42.850 & -35.455 & & & & \\
\hline
\end{tabular}

Table 6. Parameters of pseudo-second order model for $\mathrm{As}(\mathrm{V})$ adsorption on both zeolites.

\begin{tabular}{|c|c|c|c|c|c|c|c|c|}
\hline \multirow[b]{2}{*}{$\operatorname{As}(\mathrm{V})\left(\mathrm{mg} \cdot \mathrm{L}^{-1}\right)$} & \multicolumn{4}{|c|}{ WMOD Zeolite } & \multicolumn{4}{|c|}{ PMOD Zeolite } \\
\hline & Dose (g) & $k_{2}\left(g \cdot \mathrm{mg}^{-1} \cdot \mathrm{min}^{-1}\right)$ & $q_{2}\left(\mathrm{mg} \cdot \mathrm{g}^{-1}\right)$ & $R^{2}$ & Dose (g) & $k_{2}\left(g \cdot \mathrm{mg}^{-1} \cdot \mathrm{min}^{-1}\right)$ & $q_{2}\left(\mathrm{mg} \cdot \mathrm{g}^{-1}\right)$ & $R^{2}$ \\
\hline 8.5 & 1 & 5.4975 & 0.8446 & 0.9999 & 1 & 1.0408 & 0.8347 & 0.9999 \\
\hline 1.45 & 1 & 54.572 & 0.1593 & 0.9999 & 1 & 14.7158 & 0.1430 & 0.9999 \\
\hline 0.72 & 1 & 206.4923 & 0.0733 & 0.9999 & 1 & 3.5646 & 0.0687 & 0.9999 \\
\hline 0.45 & 0.05 & 0.8646 & 0.8591 & 0.9999 & 0.05 & 61.2817 & 0.0192 & 0.9999 \\
\hline 0.10 & 0.01 & 0.8441 & 0.9487 & 0.9999 & 0.03 & 26.7142 & 0.0073 & 0.9999 \\
\hline
\end{tabular}

$$
\ln \left(\frac{C_{t}}{C_{o}}-\frac{1}{1+M K_{b p}}\right)=\ln \left(\frac{M K_{b p}}{1+M K_{b p}}\right)-\left(\frac{1+M K_{b p}}{M K_{b p}}\right) \beta S_{s} t
$$

where $C_{o}$ is the initial solute concentration $(\mathrm{mg} / \mathrm{L}), C_{t}$ is the solute concentration after time $t(\mathrm{mg} / \mathrm{L}), K_{b q}$ is the constant obtained by multiplying the Langmuir constants $q_{m}$ and $b(\mathrm{~L} / \mathrm{g}), M$ is the mass of the adsorbent per unit volume of particle free adsorbate solution $(\mathrm{g} / \mathrm{L}), S_{s}$ is the external surface area of the adsorbent per unit volume of particle free slurry $\left(\mathrm{cm}^{-1}\right)$, and $\beta$ the mass transfer coefficient $(\mathrm{cm} / \mathrm{s})$. Plots of $\ln \left\{C_{t} / C_{o}-[1 /(1+\mathrm{MKbq})]\right\}$ vs $t$ are shown in Figure 4.

The $\beta$ values were obtained from the slope and were $9.06 \times 10^{-3} \mathrm{~cm} / \mathrm{s}$ and $8.86 \times 10^{-3} \mathrm{~cm} / \mathrm{s}$ for the WMOD and PMOD zeolites, respectively. The mass transfer coefficients for both zeolites were higher than those for activated alumina $\left(7.2 \times 10^{-3} \mathrm{~cm} / \mathrm{s}\right)$ reported by Sarvinder and Pant [47].

\subsection{Regeneration of Exhausted WMOD Zeolite}

The WMOD zeolite showed potential for better performance on $\mathrm{As}(\mathrm{V})$ adsorption than the PMOD zeolite. The WMOD zeolite was accelerated aged at the point that surface of the zeolite was saturated with As(V) species and the removal was not enough to reach the con-

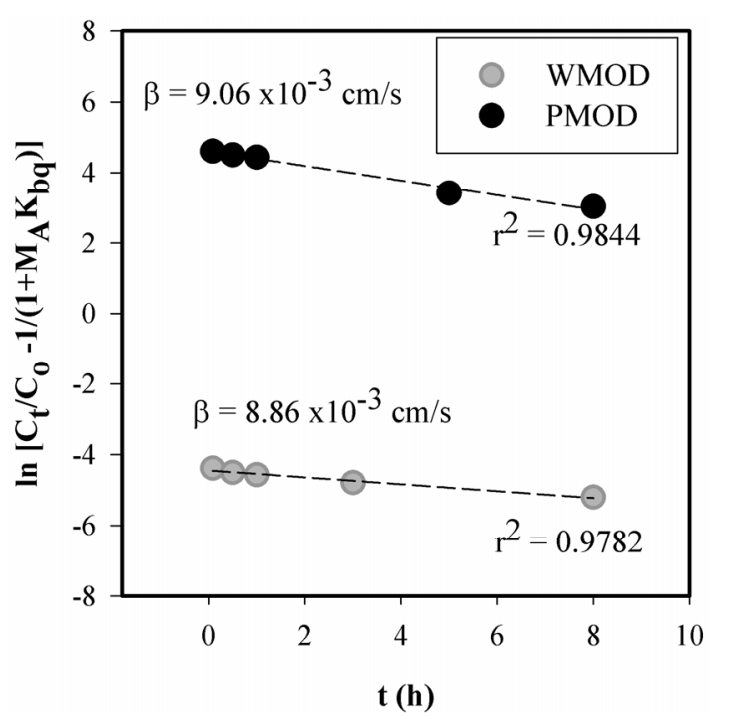

Figure 4. Estimation of the mass transfer coefficient for the adsorption of $\mathrm{As}(\mathrm{V})$ on the WMOD and PMOD zeolites $\left[C_{o}=\right.$ $0.72 \mathrm{mg} / \mathrm{L} ; \mathrm{pH}=7$; dosage zeolite $=1 \mathrm{~g}]$.

centration required in the effluent. The WMOD was regenerated and the resultant material was retested to evaluate its regeneration capacity. The WMOD zeolite was exhausted with As(V) using different high concentrations; zeolite was not substituted in any cycle. Figure 5 shows the As(V) removal of the fresh, exhausted and 

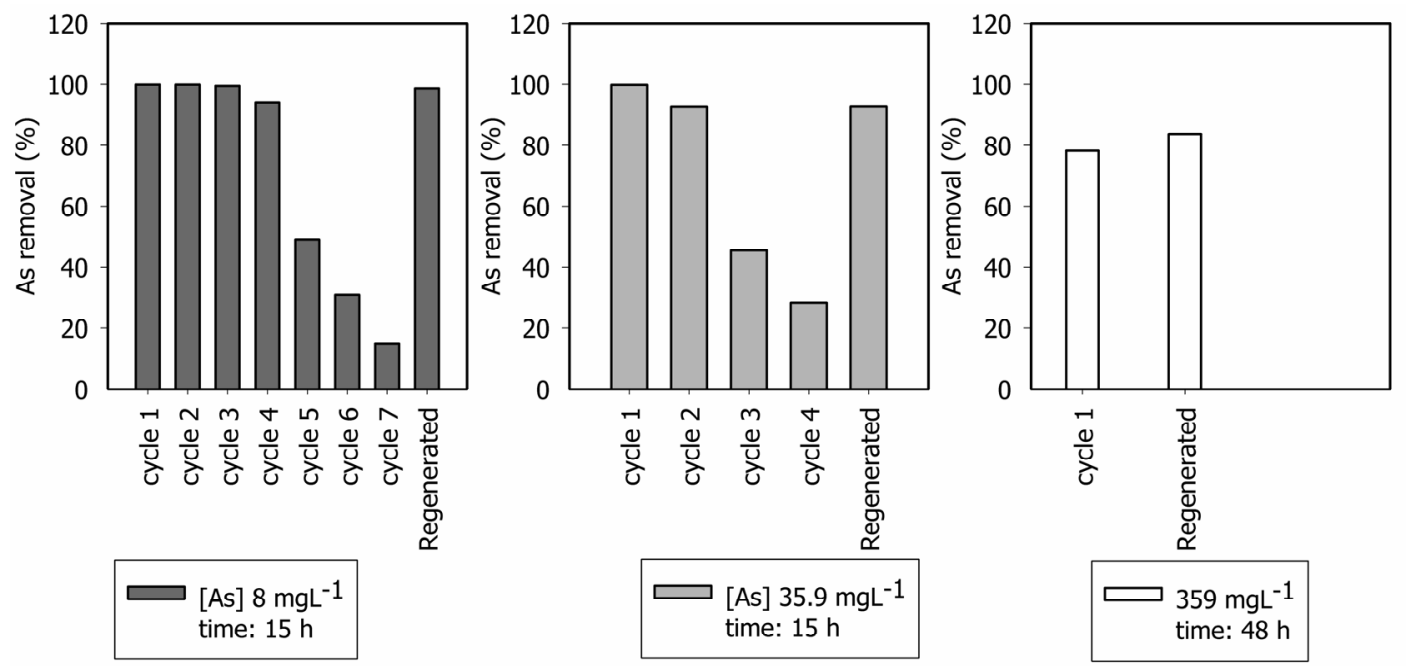

Figure 5. As(V) removal on the fresh, exhausted and regenerated WMOD zeolites.

regenerated zeolites. The WMOD zeolite was able to remove $\mathrm{As}(\mathrm{V})$ to concentrations lower than $0.01 \mathrm{mg} / \mathrm{L}$ from a solution of $8 \mathrm{mg} / \mathrm{L}$.

This behavior was observed during three cycles; after the fourth cycle, the adsorption capacity decreased progressively. In the seventh cycle, the WMOD zeolite only removed $15 \%$ of the $A s(\mathrm{~V})$. The total $\mathrm{As}(\mathrm{V})$ adsorbed was $3.94 \mathrm{mg} / \mathrm{g}$ of zeolite. Similar results were obtained when a concentration of $35.9 \mathrm{mg} / \mathrm{L}$ was used. In this case, the zeolite adsorbed $9.56 \mathrm{mg}$ of $\mathrm{As}(\mathrm{V}) / \mathrm{g}$ of zeolite. In both experiments, there was no leaching of aluminum from the zeolitic material to the solution.

An additional experiment was performed with an $\mathrm{As}(\mathrm{V})$ solution of $359 \mathrm{mg} / \mathrm{L}$; after $48 \mathrm{~h}$, the enhanced zeolite adsorbed $78.22 \%$, that is, $28.08 \mathrm{mg} \mathrm{As}(\mathrm{V}) / \mathrm{g}$ of zeolite. After this experiment, aluminum was detected in the residual solution $(0.91 \mathrm{mg} / \mathrm{L})$, indicating that aluminum was released from the zeolite to the solution. The $\mathrm{As}(\mathrm{V})$ of the exhausted materials was desorbed using a $\mathrm{NaOH}$ solution. For the zeolites exhausted with solutions of 8 $\mathrm{mg} / \mathrm{L}$ and $35.9 \mathrm{mg} / \mathrm{L}$, the $\mathrm{As}(\mathrm{V})$ desorbed was $41 \%$ and $57 \%$, respectively. For the zeolite exhausted with 359 $\mathrm{mg} / \mathrm{L}$, only $14 \%$ of the $\mathrm{As}(\mathrm{V})$ was desorbed.

The desorbed $\mathrm{As}(\mathrm{V})$ could be recovered in controlled conditions as a salt and could be evaluated the possibility of application in the electronic, textile and glass industries. During the desorption trials, aluminum was also released. Accordingly, the zeolites were retreated with an aluminum solution as described in Section 2.4.

All of the regenerated zeolites exhibited the same As (V) adsorption capacity compared with the original functionalized zeolite. These results indicated that the WMOD zeolite has a high adsorption capacity for $\mathrm{As}(\mathrm{V})$ removal from water solutions model. WMOD zeolite is easily regenerable and could be a good low-cost material for drinking water and wastewater treatment.

\section{Conclusions}

WMOD is a new material prepared by two-step simple process. In the first step, the fly ash is directly transformed with excellent yield (100\%) to W zeolite by using one of the lowest amounts of $\mathrm{KOH}$ per gram of fly ash $(0.33)$ and soft conditions $\left(175^{\circ} \mathrm{C}, 16 \mathrm{~h}\right)$.

In a second step, the $\mathrm{W}$ zeolite surface is functionalized by ionic exchange with Al (III) (WMOD) to promote $\mathrm{As}(\mathrm{V})$ adsorption capacity.

According with our findings, WMOD zeolite is chemical and mineralogically stable in the $\mathrm{pH}$ range $3-10$. It is able to remove $\mathrm{As}(\mathrm{V})$ anions from concentrated aqueous solutions $(8 \mathrm{mg} / \mathrm{L})$ to meet the value recommended by the WHO for drinking water $(0.01 \mathrm{mg} / \mathrm{L})$. The presence of carbonates ions only affected the zeolite's performance when the ions' concentration was higher than $500 \mathrm{mg} / \mathrm{L}$. One major advantage of the WMOD zeolite is that the spent WMOD zeolite can be regenerated by adding fresh aluminum salt and its high $\mathrm{As}(\mathrm{V})$ adsorption capacity can be recovered.

The thermodynamic and kinetic studies of $\operatorname{As}(\mathrm{V})$ on PMOD and WMOD are fundamental in the technological development to establish an innovative process to treat drinking water. The final results could contribute in an important way to find an useful low-cost process to remove $\mathrm{As}(\mathrm{V})$ from the contaminated groundwater from arid and semi-arid regions in Mexico and the world.

\section{Acknowledgements}

This research was funded by Sener-Conacyt-Hidrocarburos 144453 project, FOMIX-COAH 62158 and FOMIXCOAH-C14-149610 projects, Mexico.

A. Medina acknowledges M. S. García-Guillermo for her contribution to this work and to CONACyT, Mexico, for the scholarship provided. 


\section{REFERENCES}

[1] C. Perego, R. Bagatin, M. Tagliabue and R. Vignola, "Zeolites and Related Mesoporous Materials for Multi-Talented Environmental Solutions," Microporous and Mesoporous Materials, Vol. 166, No. 1, 2013, pp. 37-49. doi:10.1016/j.micromeso.2012.04.048

[2] Comisión Nacional del Agua, "Estadísticas del Agua en México," 2013.

http://www.conagua.gob.mx/CONAGUA07/Noticias/EA M2010.pdf

[3] M. A. Armienta and N. Segovia, "Arsenic and Fluoride in the Groundwater of Mexico," Environmental Geochemistry and Health, Vol. 30, No. 4, 2008, pp. 345-353. doi:10.1007/s10653-008-9167-8

[4] M. M. Meza, M. J. Kopplin, J. L. Burgess and A. J. Gandolfi, "Arsenic Drinking Water Exposure and Urinary Excretion among Adults in the Yaqui Valley, Sonora, Mexico," Environmental Research, Vol. 96, No. 2, 2004, pp. 119-126. doi:10.1016/j.envres.2003.08.010

[5] M. F. Díaz, "Arsenic in Scales of Drinking Water Distribution Networks in the North of Mexico and Its Detachment," 2013.

http://www.agualatinoamerica.com/docs/pdf/030405\%20 Nivel\%203.pdf

[6] T. Yoshida, H. Yamauchi and G. Fan-Sun, "Chronic Health Effects in People Exposed to Arsenic via the Drinking Water: Dose-Response Relationships in Review," Toxicology Applied Pharmacology, Vol. 198, No. 3, 2004, pp. 243-252. doi:10.1016/j.taap.2003.10.022

[7] H. K. Hansen, P. Nuñez and R. Grandon, "Electrocoagulation as a Remediation Tool for Wastewaters Containing Arsenic," Minerals Engineering, Vol. 19, No. 5, 2006, pp. 521-524. doi:10.1016/j.mineng.2005.09.048

[8] I. Peleanu, M. Zaharescu, I. Rau, M. Crisan, A. Jitianu and A. Meghea, "Nanocomposite Materials for As(V) Removal by Magnetically Intensified Adsorption," Separation Science Technology, Vol. 37, No. 16, 2002, pp. 3693-3701. doi:10.1081/SS-120014827

[9] T. S. Anirudhan and M. R. Unnithan, "Arsenic(V) Removal from Aqueous Solutions Using an Anion Exchanger Derived from Coconut Coir Pith and Its Recovery," Chemosphere, Vol. 66, No. 1, 2007, pp. 60-66.

[10] T. F. Lin, C. C. Liu and W. H. Hsieh, "Adsorption KinetIcs and Equilibrium of Arsenic onto an Iron-Based Adsorbent and an Ion Exchange Resin," Water Science Technology Water Supply, Vol. 6, No. 2, 2006, pp. 201-207.

[11] A. E. Pagana, S. D. Sklari, E. S. Kikkinides and V. T. Zaspalis, "Microporous Ceramic Membrane Technology for the Removal of Arsenic and Chromium Ions from Contaminated Water," Microporous and Mesoporous Materials, Vol. 110, No. 1, 2008, pp. 150-156. doi:10.1016/j.micromeso.2007.10.013

[12] C. L. Chuang, M. Fan, M. Xu, R. C. Brown, S. Sung, B. Saha and C. P. Huang, "Adsorption of Arsenic(V) by Activated Carbon Prepared from Oat Hulls," Chemosphere, Vol. 61, No. 4, 2005, pp. 478-483. doi:10.1016/j.chemosphere.2005.03.012

[13] S. Bang, M. Patel, L. Lippincott and X. Meng, "Removal of Arsenic from Groundwater by Granular Titanium Dioxide Adsorbent," Chemosphere, Vol. 60, No. 3, 2005, pp. 389-397. doi:10.1016/j.chemosphere.2004.12.008

[14] M. P. Elizalde-González, J. Mattusch and R. Wennrich, "Application of Natural Zeolites for Preconcentration of Arsenic Species in Water Samples," Journal Environmental Monitoring, Vol. 3, No. 1, 2001, pp. 22-26. doi:10.1039/b006636m

[15] C. Y. Chen, T. H. Chang, J. T. Kuo, Y. F. Chen and Y. C. Chung, "Characteristics of Molybdate-Impregnated Chitosan Beads (MICB) in Terms of Arsenic Removal from Water and the Application of a MICB-Packed Column to Remove Arsenic from Wastewater," Bioresource Technology, Vol. 99, No. 16, 2008, pp. 7487-7494. doi:10.1016/j.biortech.2008.02.015

[16] H. K. Hansen, A. Ribeiro and E. Mateus, "Biosorption of Arsenic(V) with Lessonia Nigrescens," Minerals Engineering, Vol. 19, No. 5, 2006, pp. 486-490. doi:10.1016/j.mineng.2005.08.018

[17] S. Kuriakose, T. S. Singh and K. K. Pant, "Adsorption of As(III) from Aqueous Solution onto Iron Oxide Impregnated Activated Alumina," Water Quality Research, Journal of Canada, Vol. 39, No. 3, 2004, pp. 258-266. http://www.cawq.ca/cgi-bin/journal/abstract.cgi?language $=$ english\&pk_article $=27$

[18] S. Kundu, S. S. Kavalakatt, A. Pal, S. K. Ghosh, M. Mandal and T. Pal, "Removal of Arsenic Using Hardened Paste of Portland Cement: Batch Adsorption and Column Study," Water Research, Vol. 38, No. 17, 2004, pp. 37803790. doi:10.1016/j.watres.2004.06.018

[19] O. Eljamal, K. Sasaki and T. Hirajima, "Sorption Kinetic of Arsenate as Water Contaminant on Zero Valent Iron," Journal of Water Resource and Protection, Vol. 5, No. 6, 2013, pp. 563-567. doi:10.4236/jwarp.2013.56057

[20] S. Shevade and R. G. Ford, "Use of Synthetic Zeolites for Arsenate Removal from Pollutant Water," Water Research, Vol. 38, No. 14-15, 2004, pp. 3197-3204. doi:10.1016/j.watres.2004.04.026

[21] C. Resmini, H. Gracher, N. Cabral, E. Angioletto, A. Resmini, A. M. Bernardin, M. R. da Rocha and L. da Silva, "Synthesis of 4A Zeolites from Kaolin for Obtaining 5A Zeolites through Ionic Exchange for Adsorption of Arsenic," Materials Science and Engineering: B, Vol. 177, No. 4, 2012, pp. 345-349. doi:10.1016/j.mseb.2012.01.015

[22] A. M. Ziyath, P. Mahbub, A. Goonetilleke, M. O. Adebajo, S. Kokot and A. Oloyede, "Influence of Physical and Chemical Parameters on the Treatment of Heavy Metals in Polluted Stormwater Using Zeolite-A Review," Journal of Water Resource and Protection, Vol. 3, No. 20, 2011, pp. 758-767. doi:10.4236/jwarp.2011.310086

[23] A. Medina, P. Gamero, J. M. Almanza, A. Vargas, A. Montoya, G. Vargas and M. Izquierdo, "Fly Ash from a Mexican Mineral Coal II. Source of W Zeolite and Its Effectiveness in Arsenic (V) Adsorption," Journal Hazardous Materials, Vol. 181, No. 1-3, 2010, pp. 91-104. doi:10.1016/j.jhazmat.2010.04.102

[24] X. Querol, N. Moreno, J. C. Umaña, A. Alastuey, E. Her- 
nandez, A. Lopez-Soler and F. Plana, "Synthesis of Zeolites from Coal Fly Ash: An Overview," International Journal of Coal Geology, Vol. 50, No. 1-4, 2002, pp. 413-423. doi:10.1016/S0166-5162(02)00124-6

[25] J. Li, Z. Zhang, W. Khunjar and K. Zhao, "Enhanced Nutrient Sequestration from Swine Wastewater Using Zeolite Synthesized from Fly Ash Integrated with Surface Amendment Technique," Fuel, Vol. 111, No. 20, 2013, pp. 57-65. doi:10.1016/j.fuel.2013.04.019

[26] N. M. Musyoka, L. Petrik and E. Hums, "Synthesis of Zeolite A, X and P from a South African Coal Fly Ash," Advanced Materials Research, Vol. 512-515, 2012, pp. 1757-1762.

doi:10.4028/www.scientific.net/AMR.512-515.1757

[27] M. S. Onyango, Y. Kojima, O. Aoyi, E. C. Bernardo and H. Matsuda, "Adsorption Equilibrium Modeling and Solution Chemistry Dependence of Fluoride Removal from Water by Trivalent-Cation-Exchanged Zeolite F-9," Journal of Colloid and Interface Science, Vol. 279, No. 2, 2004, pp. 341-350. doi:10.1016/j.jcis.2004.06.038

[28] P. Kumar, P. D. Jadhav, S. S. Rayalu and S. Devotta, "Surface-Modified-Zeolite a Sequestration of Arsenic and Chromium Anions," Current Science, Vol. 92, No. 4, 2007, pp. 512-517.

http://www.currentscience.ac.in/cs/Downloads/article_id 092_04_0512_0517_0.pdf

[29] S. S. Gupta and K. G. Bhattacharyya, "Kinetics of AdSorption of Metal Ions on Inorganic Materials: A Review," Advances in Colloid and Interface Science, Vol. 162, No. 1-2, 2011, pp. 39-58. doi:10.1016/j.cis.2010.12.004

[30] D. Mohan and C. U. Pittman, "Arsenic Removal from Water/Wastewater Using Adsorbents-A Critical Review," Journal Hazardous Materials, Vol. 142, No. 1-2, 2007, pp. 1-53. doi:10.1016/j.jhazmat.2007.01.006

[31] A. Medina, P. Gamero, X. Querol, N. Moreno, B. de León, M. Almanza, G. Vargas, M. Izquierdo and O. Font, "Fly Ash from a Mexican Mineral Coal I: Mineralogical and Chemical Characterization," Journal Hazardous Materials, Vol. 181, No. 1-3, 2010, pp. 82-90. doi:10.1016/j.jhazmat.2010.04.096

[32] Y. Xu, A. Ohki and S. Maeda, "Adsorption of As(V) by Used Aluminum-Loaded Shirasu Zeolites," Chemistry Letters, Vol. 27, No. 10, 1998, pp. 1015-1016. doi:10.1246/cl.1998.1015

[33] C. Collela, D. Caputo, B. de Genaro and B. E. Torraca, "Ion Exchange Equilibria in a Synthetic Merlinoite," Studies and Surface Science and Catalysis, Vol. 154, 2004, pp. 1920-1928. doi:10.1016/S0167-2991(04)80728-6

[34] B. M. Skofteland, O. H. Ellestad and K. P. Lillerud, "Potassium Merlinoite Crystallization, Structural and Thermal Properties," Microporous Mesoporous Materials, Vol. 43, No. 1, 2001, pp. 61-71. doi:10.1016/S1387-1811(00)00347-4

[35] A. J. Celestian, J. B. Parise, A. Tripathi, A. Kvick and G. M. V. Vaughan, " $\left(\mathrm{K}_{4} \mathrm{Li}_{4}\right) \mathrm{Al}_{8} \mathrm{Ge}_{8} \mathrm{O}_{32} \cdot 8 \mathrm{H}_{2} \mathrm{O}$ : An $\mathrm{Li}^{+}-\mathrm{Ex}-$ changed Potassium Alumino-Germanate with the Zeolite Gismondine (GIS) Topology," Acta Crystallographic Section C, Vol. 59, No. 8, 2003, pp. i74-i76.
doi:10.1107/S0108270103011739

[36] A. Tripathi, J. B. Parise, S. J. Kim, Y. Lee, G. M. Johnson and Y. S. Uh, "Structural Changes and Cation Site Ordering in $\mathrm{Na}$ and $\mathrm{K}$ Forms of Aluminogermanates with the Zeolite Gismondine Topology," Chemistry Materials, Vol. 12, No. 12, 2000, pp. 3760-3769. doi: $10.1021 / \mathrm{cm} 000459 \mathrm{~s}$

[37] J. W. Mortier, "Compilation of Extra Framework Sites in Zeolites," Butterworth Scientific Limited, Surrey, 1982.

[38] A. Kilislioglu and B. Bilgin, "Thermodynamic and Kinetic Investigations of Uranium Adsorption on Amberlite IR-118H Resin," Applied Radiation and Isotopes, Vol. 58, No. 2, 2003, pp. 155-160. doi:10.1016/S0969-8043(02)00316-0

[39] T. M. Suzuki, J. O. Bomani, H. Matsunaga and T. Yokoyama, "Preparation of Porous Resin Loaded with Crystalline Hydrous Zirconium Oxide and Its Application to the Removal of Arsenic," Reactive and Functional Polymers, Vol. 43, No. 1-2, 2000, pp. 165-172. doi:10.1016/S1381-5148(99)00038-3

[40] P. B. Bhakat, A. K. Gupta, S. Ayoob and S. Kundu, "Investigations on Arsenic(V) Removal by Modified Calcined Bauxite," Colloids and Surfaces A: Physicochemical and Engineering Aspects, Vol. 281, No. 1-3, 2006, pp. 237-245. doi:10.1016/j.colsurfa.2006.02.045

[41] F. Di Natale, A. Erto, A. Lancia and D. Musmarra, "Experimental and Modelling Analysis of As(V) Ions Adsorption on Granular Activated Carbon," Water Research, Vol. 42, No. 8-9, 2007, pp. 2007-2016. doi:10.1016/j.watres.2007.12.008

[42] E. Oguz, "Equilibrium Isotherms and Kinetics Studies for the Sorption of Fluoride on Light Weight Concrete Materials," Colloids and Surface A. Physicochemical and Engineering Aspects, Vol. 295, No. 1-3, 2007, pp. 258-263. doi:10.1016/j.colsurfa.2006.09.009

[43] Ö. Yavuz, Y. Altunkaynak and F. Güzel, "Removal of Copper, Nickel, Cobalt and Manganese from Aqueous Solution by Kaolinite," Water Research, Vol. 37, No. 4, 2003, pp. 948-952. doi:10.1016/S0043-1354(02)00409-8

[44] D. Mohan and K. P. Singh, "Single- and Multi-Component Adsorption of Cadmium and Zinc Using Activated Carbon Derived from Bagasse-An Agricultural Waste," Water Research, Vol. 36, No. 9, 2002, pp. 2304-2318. doi:10.1016/S0043-1354(01)00447-X

[45] Y. S. Ho and G. A. McKay, "A Comparison of Chemisorption Kinetic Models Applied to pollutant Removal on Various Sorbents," Transactions of the Institution of Chemical Engineers, Vol. 76, No. 2, 1998, pp. 332-340. doi:10.1205/095758298529696

[46] G. McKay, M. S. Otterburn and A. G. Sweeney, "Surface Mass Transfer Processes during Color Removal from Effluent Using Silica," Water Research, Vol. 15, No. 3, 1981, pp. 327-331. doi:10.1016/0043-1354(81)90036-1

[47] S. T. Sarvinder and K. K. Pant, "Equilibrium, Kinetics and Thermodynamic Studies for Adsorption of As(III) on Activated Alumina," Separation Purification Technology, Vol. 36, No. 2, 2004, pp. 139-147. doi:10.1016/S1383-5866(03)00209-0 